\title{
Entrepreneurial teams' acquisition of talent: a two-sided approach
}

by

\author{
Florence Honoré \\ Iowa State University
}

\author{
Martin Ganco \\ University of Wisconsin-Madison
}

\begin{abstract}
CES 16-45
November, 2016

The research program of the Center for Economic Studies (CES) produces a wide range of economic analyses to improve the statistical programs of the U.S. Census Bureau. Many of these analyses take the form of CES research papers. The papers have not undergone the review accorded Census Bureau publications and no endorsement should be inferred. Any opinions and conclusions expressed herein are those of the author(s) and do not necessarily represent the views of the U.S. Census Bureau. All results have been reviewed to ensure that no confidential information is disclosed. Republication in whole or part must be cleared with the authors.

To obtain information about the series, see www.census.gov/ces or contact J. David Brown, Editor, Discussion Papers, U.S. Census Bureau, Center for Economic Studies 5K034A, 4600 Silver Hill Road, Washington, DC 20233, CES.Papers.List@census.gov. To subscribe to the series, please click here.
\end{abstract}




\begin{abstract}
While it is crucial for startups to hire high human capital employees, little is known about what drives the hiring decisions. Considering the stakes for both startups and their hires (i.e., joiners), we examine the phenomenon using a two-sided matching model that explicitly reveals the preferences of each side. We apply the model to a sample of startups from five technological manufacturing industries while examining a range of variables grounded in prior work on startup human capital. The analysis is based on the Longitudinal Employer Household dynamics from the U.S. Census Bureau. Our findings indicate that, in the context of entrepreneurship, both startups and joiners rely heavily on signals of quality. Further, quality considerations that are important for the match play a minimal role in determining earnings. Our approach refines our understanding of how entrepreneurial human capital evolves.
\end{abstract}

\footnotetext{
* DISCLAIMER: Any opinions and conclusions expressed herein are those of the author(s) and do not necessarily represent the views of the U.S. Census Bureau. All results have been reviewed to ensure that no confidential information is disclosed. ACKNOWLEDGEMENTS: This research uses data from the Census Bureau's Longitudinal Employer Household Dynamics Program, which was partially supported by the following National Science Foundation Grants SES-9978093, SES-0339191 and ITR-0427889; National Institute on Aging Grant AG018854; and grants from the Alfred P. Sloan Foundation. This research was also supported by the Kauffman Foundation Grant “The Antecedents and Consequences of Individuals’ Mobility \& Entrepreneurship”.
} 


\section{INTRODUCTION}

Startups are important economic drivers of innovation and economic growth. One of the crucial resources startups have to acquire and manage is human capital (Coff, 1997; Cooper, Gimeno-Gascon, and Woo, 1994; Eisenhardt and Schoonhoven, 1990). Human capital is determined by knowledge, skills and ability (e.g. Ployhart and Moliterno, 2011) that reside in the startups' founding teams and their first hires. In many cases, early human capital is the only resource on which startups can rely when implementing entrepreneurial ideas and attracting funding (Shane, 2000; Shane and Stuart, 2002). While there is a handful of studies on the formation of entrepreneurial teams (e.g., Clarysse \& Moray, 2004; Forbes et al., 2006; Ruef et al., 2003), there is relatively little research examining hiring decisions of startups as the result of a match between the employee and the firm.

On one hand, early startup hires (i.e., joiners) represent a distinct category of employees who have a unique set of preferences and who operate in a highly uncertain setting of entrepreneurial firms (Sauermann and Roach, 2015). Some scholars have argued that startup joiners should be studied as a distinct entity in the context of entrepreneurship research (Sauermann and Roach, 2015).

On the other hand, startups represent a potential employer that is different in many respects from established firms. Startups face liability of newness and smallness and thus have a higher likelihood of failure. Startups often do not have adequate resources for human resource management and development (Cardon \& Stevens, 2004; Katz and Welbourne, 2002). The recruitment of new hires is frequently ad hoc and performed by few key employees such as the founder (Katz and Welbourne, 2002).

While the mutual selection between the startups and joiners is an important and potentially unique phenomenon, we know relatively little about what the drivers are. We address this research 
gap by examining the drivers of the startup hiring decisions and outcomes while focusing on the hires of individuals with high human capital and variables identified in prior human capital research as playing a role in the context of startup formation. These factors include education, prior work experience including experience in the target industry (i.e., the industry entered by the startup) and prior entrepreneurial experience (Shane, 2000; Agarwal et al., 2004), prior earnings, and team size (e.g., Campbell et al., 2012b; Agarwal et al., 2016; Wezel et al., 2006). We also include multiple demographical characteristics that may play a role in the matching (Ruef et al., 2003).

We study the mutual selection between the startups and joiners in a given labor market using a two-sided matching model. This specific modeling approach allows us to isolate the preferences of both startups and joiners as they compete for the best firms and employees. The two-stage matching model that we employ, further allows isolating the effect of the variables on selection from their effect on employee earnings received while at the startup. The approach addresses the common concern that earnings are a function of both selection and on-the-job performance as driven by unobserved factors.

Our study focuses on the following research questions: 1) what characteristics of the startup's human capital affect the joiners' decision to work for a given startup, i.e. what makes a startup an attractive partner relative to other startups? 2) What characteristics of the joiner's human capital affect the startup's decision to hire a given joiner, i.e. what makes a potential joiner an attractive hire on the labor market relative to other potential hires? 3) What determines earnings received by new startup employees?

We study the questions in the context of five technological industries. We include industries in which human capital likely plays an important role such as computers, electrical components and equipment manufacturing (e.g., Colombo and Grilli, 2005; Agarwal et al., 2004). Our data source is the U.S. Census Bureau employee-employer linked dataset (Longitudinal Employer Household 
Dynamics, LEHD) covering startups that had at least one hire and were founded between 2000 and 2006 in eighteen U.S. states in the five technological industries. The sample includes the entire population of such startups.

To summarize our main findings, we find that startups with large and college-educated founding teams are more attractive as employers. Finer-grain quality characteristics such as prior experience of the founding team in the target industry, prior entrepreneurial experience or their prior earnings do not seem to play a role. These results suggest that startup joiners make decisions based on signals. Such findings may contrast with prior research highlighting the importance of founders' target industry experience for startup performance (Agarwal et al., 2004; Klepper and Sleeper, 2005). We also find that joiners with target industry experience of three years or more are more attractive as potential hires while other quality signals such as prior earnings again do not affect selection. In the second stage of our model, after selection is conditioned out, we find that joiners' earnings one year after being hired are positively affected by joiners' earnings prior to being hired and earnings of the startup founding team before the startup creation. Consequently, we find that different human capital quality characteristics determine earnings and hiring. Significant uncertainty associated with entrepreneurial context may lead to selection and earnings determination to be driven by "first-order" drivers of each outcome. These characteristics are separate for each outcome - signals determine selection and prior earnings drive current earnings after selection is controlled for. We also find that gender matters for both selection and earnings while foreign status and age matter only for selection. This may reflect demographic preferences such as homophily (Ruef et al., 2003) or even biases such as gender discrimination (Khazan, 2015; Altonji and Blank, 1999; McCall, 2001).

The study contributes to the literature on the formation and growth of entrepreneurial firms through hiring by examining the antecedents of selection of early employees. The paper applies the 
two-sided matching model used in strategy (Mindruta, 2015; Mindruta et al., 2016) in the context of entrepreneurship. The paper thus describes an approach to handling endogenous relationships when instruments are not readily available (Sørensen, 2007; Park, 2013; Chen, 2013).

\section{HIRING IN THE ENTREPRENEURIAL LABOR MARKET}

Human capital can be defined as knowledge, skills and ability of individuals (e.g., Ployhart and Moliterno, 2011). In the early stages, startups' human capital originates from their founding teams. When startups survive the initial stage and embark on growth, they acquire new human capital through hiring talented new employees. Human capital embedded in the founding team and in the hired employees (i.e., joiners) is a key determinant of future firm performance (Coff, 1997; Campbell et al., 2012a). However, when individuals select firms that they want to work for and startups recruit potential employees, they may base their decisions on observable signals of human capital (Bidwell and Mollick, 2015). Because startups' hiring is not as developed or as organized as that of established firms and the entrepreneurial outcomes are uncertain, the process through which signals of human capital affect hiring in this context may have unique properties.

Following Roach and Sauermann (2015), we refer to potential hires of startups as joiners. Roach and Sauermann (2015) conclude that joiners are different from both entrepreneurs and employees of established firms. For instance, they have a taste preference for work in a startup which may be a diverse and dynamic environment but may be unwilling to take the risks associated with starting their own firm. In the context of our approach, we assume that joiners maximize their utility associated with working for a focal firm. In other words, conditional on being willing to take a position at a startup, joiners will prefer to work for a startup that they estimate will maximize this 
utility. $^{2}$ Multiple signals about the quality of human capital of the startup will likely influence the choices made by joiners.

Consistent with executives' and firms' mutual selection (Pan, 2015), both startups and joiners have preferences for their partner. This phenomenon is captured by the two-sided matching market described by Roth and Sotomayor (1992). Because the agents want to maximize the utility they obtain from their choices, the agents compete to enter into a relationship with the highest quality partner. The competition leads to an equilibrium in which none of the agents from each side has an incentive to break away and find another partner (Gale and Shapley, 1962; Roth and Sotomayor, 1990).

Because the focus of the selection of partners is in a technological context, the selection criteria are likely based on human capital dimensions (knowledge, skills and ability). In conjunction with human capital characteristics, the selection may be driven by psychological and sociological dimensions based on observable aspects such as gender, race, foreign status and age. As a result, we include these demographic characteristics in our approach. Below, we discuss observable human capital characteristics that are present in our model as primary signals of quality in more detail:

a) Education: formal education is often considered to be the main building block of human capital (Becker, 1967). College degree is a well-known signal of productive capabilities of individuals (Spence, 1976; Weiss, 1995). Thus, founding teams with a higher share of educated team members clearly signal productivity. Founding teams with higher levels of education may also convey information about the quality of entrepreneurial opportunity. In the technological industries, innovations and particularly breakthrough innovations may rely on concepts developed in an academic setting (Shah and Panhke, 2014). For instance, significant developments in the semi-

\footnotetext{
2 The two-sided matching model assumes that all agents want to maximize their overall utility. In each group of agents, the counterpart's characteristics that maximize their utility are viewed as identical.
} 
conductor industry emerged from the research led by university researchers in combination with firms’ labs (Holbrook et al., 2000). Similarly, highly educated joiners are attractive partners for startups because they are likely to have more productive capabilities (Spence, 1973) and connections to reservoirs of knowledge from which to draw (Fleming and Sorenson, 2004). Thus, founding teams and joiners with college education are likely to be attractive partners, i.e. education positively affects their position in the pool of potential partners.

b) Prior work experience: work experience embodies both knowledge and skills acquired over time learning and performing tasks. In the context of technological startups, experience in the target industry (Agarwal et al., 2004) and entrepreneurial experience (Delmar and Shane, 2006) are likely highly relevant experiences that founding teams and joiners consider in the matching process. Prior work experience in the target industry: founding teams with target industry experience have a repository of highly relevant industry-specific knowledge. This knowledge, which can be technological, market-related, or regulation-related, gives their startups an edge over other startups without such knowledge (Agarwal et al., 2004; Chatterji, 2009). Joiners may perceive founding teams with target industry experience as likely to be more successful in terms of survival, future growth and innovation. As a result, startups with such experience may be perceived as more attractive employment opportunities providing a signal of viability of the business they join (Agarwal et al., 2004; Delmar and Shane, 2006). Startups are also likely to prefer joiners with target industry experience because workers with such experience tend to perform better (Parent, 2000). Their experience from the prior employment is highly relevant and they can even bring in new business opportunities through their knowledge of markets and technologies (Gambardella et al., 2014; Ganco, 2013; Chatterji, 2009). Consistent with such view, prior work has identified industry-specific knowledge as an important driver of wage premiums in the labor market (Abowd, Kramarz and 
Margolis, 1999). ${ }^{3}$ Overall, given the extensive prior findings of the positive effect of target industry experience on firm and individual performance, founding teams and joiners with prior experience in the target industry are likely to be attractive partners, i.e. target industry experience will positively affect their ranking in the sorting process.

Entrepreneurial experience: founding teams' entrepreneurial experience has been shown to have a positive impact on startup performance (Delmar \& Shane, 2006). Founding teams with prior entrepreneurial experience have acquired organizational knowledge on how to run a new business (Delmar \& Shane, 2006). These founding teams are also better at obtaining venture capital funding (Hsu, 2007), and are faster at securing investment and reaching milestones such as the IPO (Shane \& Stuart, 2002). These two features are attractive to joiners who took some risks by joining a startup where their employment is more precarious. Thus, founding teams with entrepreneurial experience are likely to be attractive partners, i.e. entrepreneurial experience positively affects their ranking. c) Prior earnings: Ability may be another component of human capital to consider. Ability is difficult to observe especially for startups and joiners who may not have extensive resources to perform due diligence and conduct interviews. Conditional on other observable characteristics such as education and experience, prior earnings (or rank) have been used as a signal of ability (e.g., Campbell et al., 2012b). While prior target industry experience and prior entrepreneurial experience may capture knowledge about the industry and entrepreneurial skills, controlling for these factors, prior earnings encompass more general ability that affects the individuals' ranks in a firm's hierarchy (Wezel, Cattani, and Pennings, 2006), social connections (Shaw, Duffy, Johnson, and Lockhart, 2005) and access to better information (Agarwal et al., 2013). Further, knowledge without the ability

${ }^{3}$ One factor may downplay the effect of target industry experience on the mutual selection. If most startups have extensive target industry experience, they may prefer joiners with other types of knowledge to diversify their knowledge base (Sapienza et al., 2004) and to acquire the potential to recombine knowledge and innovate (Katila and Ahuja, 2002; Fleming and Sorenson, 2001). 
to exploit it should not guarantee higher earnings, which means that prior earnings encompass more information than the acquisition of knowledge. This additional information is summarized under the general term of ability (Braguinsky et al., 2012). High ability individuals who become founders have startups that do better (Agarwal et al., 2013) and do better personally by, for instance, perceiving higher earnings (Braguinsky et al., 2012). This is an important signal for joiners for their upcoming career in the startup. Similarly, startups are likely to prefer joiners with high ability. To sum up, founding teams and joiners with high prior earnings are likely to be attractive partners, i.e. high prior earnings positively affect their ranking.

d) Entrepreneurial team size. In addition to individual-level human capital characteristics, founding teams may also signal their potential to survive and grow. Large founding teams signal two important features to joiners. First, they signal that the startups pursue a larger entrepreneurial opportunity, or high-potential opportunity requires more employees in order to start. Second, they signal that the founders were able to find the initial funding to form the team to pursue it (Geroski et al., 2010). Thus, large initial teams signal high potential and the access to resources to, at least, start realizing the potential. Large teams are also more likely to be organized into specialized roles and tasks and to exhibit complementarities of knowledge (Sine, Mitsuhashi, and Kirsch, 2006; Wezel et al., 2006). Thus, a large team can be interpreted as a multiplier effect of the human capital and conveys a positive signal of possibility of growth and career progression for the joiners and is likely to be an attractive counterpart. Large founding teams are likely to be attractive partners, i.e. founding team size positively affects their ranking.

The human capital characteristics discussed above likely also affect the joiners' earnings in the startup. Prior two-sided matching studies such as Sorenson (2007), differentiated the effect of the characteristics on selection (i.e. sorting effect) from their effect on the outcome of the partnership (i.e. influence effect). In this study, we examine this distinction on the early earnings 
obtained by the joiners. These earnings are similar to a reservation wage that joiners are willing to accept to join the startup. Indeed, the short term earnings cannot capture a performance of the partnership as often this will depend on long term outcomes when the startup reaches full potential if they do so.

\section{DATA}

\section{Data source}

One of the difficulties in studying startups' employment is getting access to data that systematically track employment history in the early stages of the new firms. To observe these employment relationships, we gained access to the Longitudinal Employer Household Dynamics (hereafter, LEHD) from the U.S. Census Bureau, which links employees to employers in the U.S. over twenty years. The LEHD is constructed from unemployment insurance records and provides quarterly information on all employees for which employers pay into the state unemployment insurance fund (McKinney \& Vilhuber, 2011). As all employers are required by law to pay unemployment insurance, the LEHD coverage is universal with the exception of self-employed workers and government workers. The LEHD is made out of three files: the Individual Characteristics File with individuals' date of birth, gender, race, education and citizenship; the Employer Characteristics File with the establishment industry, payroll, state and county; and the Employment History File that connects establishment to individuals every quarter with the individuals' earnings. We also gained access to the Longitudinal Business Data bridge to check whether the appearance of an establishment id at the state level can be connected to a new firm id at the national level and, thus, confirming the establishment of a startup.

\section{Samples}


The Census Bureau provided us with an initial extract from the LEHD that covers 30 states between 1991 and 2008. We reduced it to the 18 states with coverage starting in 1996 or before to create pre-founding measures. Further, we narrowed our sample to five technological manufacturing industries, which are at the three-digit NAICS level: Fabricated Metal Product Manufacturing; Machinery Manufacturing; Computer and Electronic Product Manufacturing; Electrical Equipment, Appliance, and Component Manufacturing; and Transportation Equipment Manufacturing (see appendices A1 and A2 for list of states and industries at the four-digit NAICS level). We chose these industries because they heavily rely on human capital when creating new products and services, and they offer fertile environment for startup creation (Carroll et al., 1996; Holbrook et al., 2000; Klepper, 2002; Klepper, 2007.

We created two samples: the startup sample and the linked joiner sample. We examine employment relationships rather than founding team relationships. To make sure we exclude founding team emergence, we started collecting employment relationships when the startups were at least 6 quarters old. Then, to make sure that we focus on hiring by young startups, we excluded startups that are more than 4 years old (Hanks et al., 1193). Our final sample was made of 1,000 startups that hired at least one joiner between their $6^{\text {th }}$ and $16^{\text {th }}$ quarter of existence.

A joiner is an individual who decided to leave his/her job to join a startup at an early stage. We then excluded joiners who did not earn at least the minimum yearly earnings of anyone with a supervisorial position in our five industries ${ }^{4}$. There are two reasons for this exclusion. First, because the LEHD is a census of all types of workers including part-time workers and workers with multiple

\footnotetext{
${ }^{4}$ The amount had to be equal or superior to an average of $\$ 52,000$ before joining the startup. This amount the minimum earnings among the average yearly earnings of the most common managerial jobs in the five industries based on the publicly available data of the Bureau of Labor Statistics. http://www.bls.gov/iag/tgs/iag 335 .htm\#earnings - converted into 2008-dollar value
} 
jobs, the sample has to be trimmed to only include workers who are integrally part of the labor market and for whom matching to a specific job economically matters. Second, if we tried to explain the startups' hiring for any kind of position, it would be difficult to come with an overarching argument that works for such a wide range and it would be difficult for the model to capture anything else than noise. Our sample of joiners is made of around 4,000 individuals.

\section{INSERT FIGURES 1 AND 2}

The samples of startups and joiners are organized into markets. A market is defined as a state-industry-year entity in which startups and joiners pair up. Structured this way, the dataset is made up of 110,000 dyads, which represent any combination between a startup and a joiner in a market. By comparison, if there was no market structure, all the startups could pair up with all the joiners and the total number of dyads would be $1,000 \times 4,000=4,000,000$. This would not make economic sense as the joiners are not permanently on the job market for five years across all states and all industries. The division of the labor market by state, industry, and year seems to be a reasonable configuration. Ninety-five percent of the labor force that switches jobs within a year remains in the same state (Molloy et al., 2011). Further, individuals who change jobs while being employed at a supervision-level job the year before are expected to have a good idea of the industry in which they want to work. As for the year, it is a convenient time period for the estimation because shorter time periods such as quarters would not have enough hiring events and the variance across observations would not be meaningful. The studied years are from 2003 to 2007. For each year, startups that are between 1 year and 3 years pair up with joiners. Around 120 markets are created which means that on average a market consists of around 900 dyads of 60 joiners and around 15 startups. The matching model that we employ implicitly assumes that both startups and individuals are aware of each other's characteristics within the market. These average numbers suggest that this 
assumption may be reasonable. Note that all the sample sizes are rounded on request of the Census Bureau for confidentiality reasons.

\section{Dependent variables}

In the matching, $\mathrm{M}_{\mathrm{ij}}=1$ when the startup i pairs up with the joiner $\mathrm{j}$. Every joiner is matched once and only once, while every startup is matched at least once.

In the outcome equation, following research on individual earnings (Braguinsky et al., 2012; Parent, 2000), we used the natural logarithm of the yearly earnings of the joiner one year after they joined in the startups. The earnings provided by the LEHD include the wages, bonuses and exercised stock options obtained during their employment at the startup. However, given the fact that joiners only worked for a year at the time of the measurement, wages are likely to make most of the earnings.

\section{Independent variables}

The startup variables and joiner variables are conceptually the same but they are measured over different time periods (see Figures 1 and 2). Here is an example. A startup created the first quarter of 2003 has its founding team determined during its $5^{\text {th }}$ quarter, so the first quarter of 2004. The founding team experience variables are measured from the beginning of the LEHD up to 2002. The startup hires a joiner in the second quarter of 2004 so during its $6^{\text {th }}$ quarter. Thus, 2004 is the year t during which the joiner is hired. Her experience variables are measured from her first appearance in the LEHD, most likely in the 1990s up to 2003 while her performance is measured in year $t+1,2005$. As the time period of measurement is clarified, we describe the variables at the individual level. The founding team variables are the averages of the founding team members' variables. 
Education is measured by a college dummy, which is coded 1 when the worker has reached at least 16 years of education (6 years of elementary school, 6 years of high school and 4 years of college) and 0 otherwise. Graduate studies are captured in the same dummy.

Target industry experience relates to the industry knowledge an individual acquires through work experience in the industry of the startup (e.g. Delmar \& Shane, 2006) and is first measured as the number of years an employee worked in the 3-digit NAICS industry of the startup before being hired in the startup. We then break down the variable into five dummy variables because the relationship was not linear. We choose the dummies so that their interpretation makes sense and their sizes in number of observations are balanced. The five dummies are the following: zero year of target industry experience; more than zero but less than or equal to 2 years; more than 2 but less than or equal to 4 years; more than 4 but less than or equal to 6 years; and strictly more than 6 years. The omitted variable is the zero year of target industry experience. For the joiners, the tails of the distribution are heavier while for the founding teams they are lighter ${ }^{5}$.

Entrepreneurial experience relates to the entrepreneurial knowledge an individual acquires and is measured by the number of times an employee was part of the founding team of a startup, i.e. was employed the first year the startup was created (e.g. Delmar \& Shane, 2006; Shane \& Stuart, 2002). Age is a proxy for the time an individual acquires general experience and is exposed to the labor market (Jovanovic, 1979). Because the relationship was not linear, it is also broken down in four dummies: less than thirty years; more than thirty but less than 40 years; more than 40 but less than fifty years; and more than fifty years.

\footnotetext{
${ }^{5}$ The number of observations per dummy cannot be disclosed.
} 
Prior earnings variable relates to the general ability of a worker and is measured by the annual earnings of the worker the year before he or she is hired by the startups (Agarwal et al., 2013; Braguinsky et al., 2012).

Team size is measured by the number of founding team members who are the number of employees of the startups at its $5^{\text {th }}$ quarter. To be included, they had to have earned at least $\$ 10,000$ yearly over their career.

Additional variables (demographics): Gender is coded 1 if the worker is a male and 0 otherwise. Race is coded 1 if the worker is white and 0 otherwise. A foreigner is coded 1 if the worker is not a U.S. citizen and 0 otherwise. Age is broken down in four dummies: less than thirty years; more than thirty but less than 40 years; more than 40 but less than fifty years; and more than fifty years.

\section{METHOD}

\section{Model}

\section{Motivations}

To answer our three research questions, we needed a model that captures the mutual aspect of the employment decision and a model that solves the endogeneity issue due to selection in the outcome equation. We opted for a two-sided matching model supplemented by an outcome equation. Two-sided matching models were originally used to determine assignment based on mutual selection between two distinct groups -universities and students during college admission (Gale and Shapley, 1962; Roth and Sotomayor, 1992). These models have become more salient in business administration research. For instance, matching models were used to explain the selection between university scientists and firms (Mindruta, 2013), between buyers and suppliers (Fudge Kamal, Honoré and Nistor, 2016), between executives and firms (Pan, 2015), between acquirers and 
targets (Park, 2013; Akkus, Cookson and Hortacsus, 2015), between biotech and pharmaceutical firms (Mindruta, Moeen and Agarwal, 2016), between venture capitalists and startups (Sørensen, 2007) and banks and firms (Chen, 2013).

Two-sided matching theory and models present three key features: the voluntary mutual selection between two groups of partners, the competition for better partners and the interdependence of the choices, which make them better tools to understand hiring by startups than discrete choice model (Park, 2013; Pan, 2015; Mindruta et al. 2016). A discrete choice model estimates the choice made by one agent although startups and joiners only enter in an employment relationship if they both agree and select each other simultaneously. Second, a discrete choice model misses the competition within each side to get the better partner from the other side. With a discrete choice model, a partner A would decide to work with a partner B and the relationship would be created while in reality, other agents on A's side might be competing for B. Finally, all these choices are interdependent - if A and B select each other, B is not in the choice set of the next agent on A's side. The matching model allows the choices of each agent to interact with the choices of the other agents in the same side.

In addition to these features, the model also assumes that each side has complete information about the agents on the other side of the match in the market. The observed matches (i.e. employment relationships) are assumed to be the "best" any agent could have obtained. The model reveals what each side's characteristics created those the matches. In other words, it reveals what characteristics made a startup preferred by joiners over the next startup. Similarly, it reveals what characteristics made a joiner preferred by startups over the next joiners. Thus, we know what joiners' and startups preferences are and the underlying ranking.

These rankings are important because they are used in the estimation of outcome. The specific matching model that we use addresses the endogeneity issue that occurs in outcome or 
performance regression (Sørensen, 2007; Chen, 2013; Park, 2013). Here is a simple example to first understand the issue in this context. We know that experienced founding teams select better joiners but we do not observe all the dimensions that make them better hires. The founding team experience is thus correlated with these unobserved dimensions. The positive effect of a founding team's experience on earnings is thus biased as it includes this extra information on joiners. A classical solution would be to use an instrument for founding team experience that does not correlate with unobserved correlated variable. However, it tends to be difficult to find viable instruments for founding team experiences or other founding team characteristics. Rather than finding the exogenous variables, the matching model relies on sorting into ranking as an exogenous variation that affects the selection between the joiners and startups but not the earnings. The sorting plays out as follows. Each agent, founding team or joiner, is ranked against the other agents in their group. The best teams are at the top of the ranking and have the opportunities to choose among all the joiners, whereas the worst teams might be pushed back and have only a few possibilities for joiners. Similarly, the joiners are also ranked and see their choice set of founding teams affected by their characteristics and the characteristics of all the other joiners. The positions in the rankings are relative and depend on each agent's characteristics. For a given match between a team and a joiner, the exogenous variation that is needed to obtain a correct estimation of the earnings is provided by the characteristics of the remaining agents. More precisely, the selection that happens between team $i$ and joiner $j$ is influenced by their own characteristics as well as the characteristics of the remaining agents. Because the characteristics of these remaining agents influence the match between $\mathrm{i}$ and $\mathrm{j}$ but do not influence the outcome of that pair, they are the exogenous variation needed for an unbiased estimation.

Assumptions 
Two distinct sides match up - the startups and the joiners. Each joiner can only be hired by one startup in a given market while startups can only hire a given quota of joiners, which makes the model a one-to-many matching model. Each startup can hire in a given market up to its quota of joiners. This comes from the fact that startups have limited resources, so even if a startup as at the top of the ranking, it is not able to hire all the joiners in the labor market. The quota is the number of joiners actually hired in a year by a given startup and it is assumed that each startup uses up its quota. These two groups pair up in a defined market. In this study, a market is defined as an industry-year-state entity. In each market, each group has complete information on the existence and characteristics of each entity in the other group. From the description of the sample and markets, we see that this assumption is plausible as each market size is made of a relatively small number of startups and joiners. Choosing specialized industries helped as opposed to for instance food service industry where individuals can easily enter and there are many hiring new firms. Finally, we assume that the outcome of the match, the joiners' earnings one year after joining, is only determined by characteristics of the startup, joiner and economic controls. In other words, there is no other transfer among partners. Joiners cannot trade lower earnings against a startup higher in the ranking, whereas startups cannot trade better joiners for higher earnings.

$$
\begin{aligned}
& \text { Equations for each market } t \\
& \qquad \begin{array}{l}
\mathrm{M}_{\mathrm{ij}} \\
=\mathrm{I}(\text { startup } \mathrm{i} \text { hires joiner } \mathrm{j}) \\
\mathrm{R}_{\mathrm{i}}^{\mathrm{s}}=\mathrm{S}_{\mathrm{i}} \beta+\mathrm{n}_{\mathrm{i}} \\
\mathrm{R}_{\mathrm{j}}^{\mathrm{i}}=\mathrm{J}_{\mathrm{j}} \gamma+\mathrm{d}_{\mathrm{j}} \\
\text { Ln earnings } \mathrm{s}_{\mathrm{ij}}=\alpha_{0}+\mathrm{S}_{\mathrm{i}} \alpha_{1}+\mathrm{J}_{\mathrm{j}} \alpha_{2}+\mathrm{C}_{\mathrm{ij}} \alpha_{3}+\mathrm{e}_{\mathrm{ij}}
\end{array}
\end{aligned}
$$

Where $\mathrm{M}_{\mathrm{ij}}=1$ when the startup i pairs up with the joiner $\mathrm{j}$ based on the equilibrium obtained from $\mathrm{R}_{\mathrm{i}}^{\mathrm{s}}$ and $\mathrm{R}_{\mathrm{j}}^{\mathrm{j}}$, the respective startup and joiner rankings. S represents the vector of the startup and 
founding team characteristics; $\mathrm{J}$ represents the vector of the joiner characteristics; and $\mathrm{C}$ represents the vector of controls. All the error terms, $\mathrm{n}_{\mathrm{i}} \mathrm{d}_{\mathrm{j}} \mathrm{e}_{\mathrm{ij}}$, are normally distributed.

\section{Equilibrium}

The utility that each participant obtains from a match is based on the ranking of the partner: the higher the ranking, the higher the utility. Thus, joiners and startups always prefer a partner with the highest ranking. However, the partner might not have an incentive to choose that counter-part. A stable equilibrium is reached if there is no blocking pair, so no partner has an incentive to deviate. In other words, the equilibrium is stable if each startup matches with the best joiner among the set of joiners willing to match with the startup and each joiner matches with the best startup among the set of startups willing to match with the joiner ${ }^{6}$. The stable equilibrium is based on group stability that has been proven to be equivalent to pair-wise stability by Roth and Sotomayor (1992). Our model is a specific case that produces a stable equilibrium that is also unique as needed for empirical estimation. This unique stable equilibrium is characterized by a set of inequalities. In a market $t$, let $i$ $\in I$ be a startup, $j \in J$ be a joiner, $j=\mu(i)$ and $i=\mu(j)$ if startup $i$ and joiner $j$ are partners in matching $\mu$, so that

$$
\begin{aligned}
& \forall i \mathrm{R}_{\mathrm{i}, \mu(\mathrm{i})}>\mathrm{R}_{\mathrm{i}, \mathrm{j}} \text { for } \forall \mathrm{j} \in\left\{\mathrm{j} / \mathrm{R}_{\mathrm{i}, \mathrm{j}}>\mathrm{R}_{\mu(\mathrm{j}), \mathrm{j}}\right\} \\
& \text { and } \forall \mathrm{j} \mathrm{Rj}_{\mu(\mathrm{j}), \mathrm{j}}>\mathrm{Rj}_{\mathrm{i}, \mathrm{j}} \text { for } \forall \mathrm{i} \in\left\{\mathrm{i} / \mathrm{Rs}_{\mathrm{i}, \mathrm{j}}>\mathrm{Rs}_{\mathrm{i}, \mu(\mathrm{i})}\right\}
\end{aligned}
$$

Our study uses Chen's method (2013) that proved the existence of a unique equilibrium (for the formal proof, see Chen, 2013) and derived the upper and lower bounds of ranking to estimate the conditional posterior distributions.

${ }^{6}$ The equilibrium can be described as follow too. The equilibrium is stable the worst employee of a startup is better off with that startup than with any worse startup. This joiner would be better off with a better startup but that startup has no incentive to hire this joiner because that startup can hire better joiners. Conversely, the equilibrium is stable if a startup is better off with its worst employee rather than with the best employee of the startup ranked right after. 


\section{Estimation}

The two-sided matching estimation can be challenging. To use a maximum likelihood estimation, we would have to obtain the likelihood function by integrating the joint density of the endogenous variables and the latent rankings conditional on the exogenous variables and the parameters: $\mathrm{p}\left(\mathrm{M}_{\mathrm{ij}}\right.$, Ln earnings $\left.\mathrm{s}_{\mathrm{ij}}, \mathrm{R}_{\mathrm{i}}^{\mathrm{s}}, \mathrm{R}_{\mathrm{j}}^{\mathrm{j}} / \mathrm{X}, \alpha, \beta, \gamma, \varkappa, \lambda, \sigma_{\mathrm{v}}^{2}\right)$. This integration over a large number of dimensions, basically the ranking of each agent, is computationally demanding. Further, as the ranking of each agent depends on the ranking of all the other agents, the integration cannot be factored into product of lower dimensions (Chen, 2013). Therefore, a simple integration of the likelihood function is not possible. Instead, a solution was developed using the Bernstein-von Mises theorem that states that the mean of Bayesian posterior distribution has the same sampling asympottic distribution as the one obtained from maximum likelihood estimation (Doob, 1949; Freedman, 1963, 1965). The solution consists of a Bayesian estimation with data augmentation and Gibbs sampling (Gelfand and Smith, 1990; Geweke, 1999). Because it is still difficult to draw directly from a joint density, Gibbs sampling is used to draw on the conditional density of each variable given the value of the others. Data augmentation means that the latent variables, the rankings, are treated as parameters. Thus, the difficult integration problem has been converted into a simulation (Sørensen, 2007; Park, 2013; Chen, 2013). In each iteration, each parameter is simulated conditional on all the other parameters and the simulated distribution converges to the conditional posterior distribution under weak regularity conditions (Roberts \& Smith, 1994). Conditional posterior distributions are obtained from the upper and lower bounds of the rankings and Bayes probability law. For the full derivation, see Chen (2013). In this estimation, we use 20,000 draws; the first ten percent of the draws are discarded for burn-in. The coefficients of the variables are the mean of these variables across the 18,000 draws. The standard deviations are also computed across the 18,000 draws. 


\section{Error terms and prior distributions}

Because the unobserved elements that can affect both the selection and the outcome may create endogeneity problem, we model the correlation among the error terms between the matching equations and the outcome equations. The relationship is set as:

$$
\mathrm{e}_{\mathrm{ij}}=x \mathrm{n}_{\mathrm{i}}+\lambda \mathrm{d}_{\mathrm{j}}+\nu_{\mathrm{ij}}, \nu_{\mathrm{ij}} \sim \mathrm{N}\left(0, \sigma^{2}{ }_{v}\right)
$$

The signs of the model are identified by requiring that $\lambda$ is superior or equal to zero, which means that joiners with higher unobserved component of their ranking position obtain higher earnings. The prior distributions are multivariate normal for $\alpha, \beta$ and $\gamma$, normal for $x$, and truncated normal for $\lambda$ (truncated on the left at zero). We chose uninformative priors with a mean of 0 and a variance of 10 following prior research (Sørensen, 2007; Park, 2013; Chen, 2013). The prior distribution of $1 /$ $\sigma^{2}{ }_{v}$ is gamma $G(2,1)$.

\section{RESULTS}

Table 1 presents the descriptive statistics of the team and joiner variables as well at the t-test statistics. The average founding team size is eight team members with a large standard deviation of almost seven team members. The founding teams' average target industry experience is 1.84 years and is significantly lower than the joiners' average target industry experience, which is around 3 years. Their average ages are also significantly different -39.48 years for the founders and 41.60 for the joiners. The founding teams' and joiners' entrepreneurial experience is similar and around 0.5. Because the sample only includes joiners who earned at least $\$ 52,000$ before joining, their prior earnings are significantly higher than the founding team members' ones $-\$ 90,732$ versus $\$ 43,004$. For this same reason, it is also important to compare earnings within each group and not across groups. The demographic characteristics are along the same lines but on average, joiners have slightly higher percentages than founding teams. Thirty percent of the joiners have a college degree 
while only twenty-one percent of the founding team members do. The percentage of male, white and foreigner joiners are also higher. Finally, it is also interesting to note that the year before joining, joiners earned on average $\$ 90,732$ while one year into their startup job, their earnings decrease on average to $\$ 72,510$.

\section{INSERT TABLE 1}

Table $2 \mathrm{a}$ presents the results of the mutual selection equation of the matching model. The mutual selection between the two partners is determined by their ranking position. The higher the rank of a partner, the most attractive this partner is to its potential counterpart. On the startup side, the share of college-educates team members is positive and significant. The average prior earnings are not significant. Nor is target industry experience or entrepreneurial experience. However, large founding teams make their startups a more attractive partner. This is presumably because larger teams signal to the joiners a bigger opportunity or an opportunity with higher potential.

Regarding the demographical characteristics, one of the age categories, average age between forty and fifty years old, makes startups less attractive partners than startups whose teams are younger than thirty years old. The share of foreigners on the team also makes a startup less attractive. In other words, teams with fewer foreigners are more attractive.

On the joiner side, the target industry experience is the most significant characteristic that makes a joiner attractive. This is in line with prior work showing that industry knowledge is important for success at the startup level (Agarwal et al., 2004) and at the individual level (Parent, 2000). The second most important characteristic is the joiner's gender. Male hires are significantly preferred. Joiners between thirty and forty years old are also preferred. 
The interpretation becomes even richer when examining startups and joiners' coefficients side-by-side and when computing the probability advantage from their coefficients ${ }^{7}$. This probability advantage represents the probability of a given agent to be chosen over another agent. Regarding education, an increase in the share of college-educated teammates by one standard deviation (20\% increase) provides a probability advantage of 3.68\%. By contrast, joiners who obtained a college degree do not have a significant advantage over joiners who did not.

Founding teams with target industry experience are not significantly more attractive than founding teams without such experience. Joiners with target industry experience of three and four years and more than six years are significantly more attractive than joiners with no target industry experience. In terms of probability advantages over joiners with no such experience, joiners with three to four years, joiners with five to six years and joiners with more than six years of target industry experience have respectively $7.43 \%, 4.66 \%$ and $6.85 \%$ more chances to be chosen by startups. Entrepreneurial experience is not significant for either side. Prior earnings are not significant for either side as well.

The effect of large teams is positive and significant at 10\%. A founding team that increases of around seven team members has a probability advantage of $3.10 \%$.

As for age, founding teams between forty-one and fifty years old have a probability disadvantage of $12.96 \%$ over teams less than thirty years old. Young founding teams are clearly more attractive to joiners. The other age categories are not significantly different from being less than thirty. Finally, the prior earnings of the founding teams and joiners are insignificant.

\footnotetext{
${ }^{7}$ The probability advantage is computed as follow: $\left\{2 *\right.$ normal cumulative distribution function $\left.\left(\mathrm{X}_{\mathrm{i}} \beta-\mathrm{X}_{\mathrm{i}} \beta\right) / 2^{\wedge} .5\right\}-1 \forall \mathrm{i} \neq$ i'
} 
Founding teams with higher share of foreigners are at a disadvantage - increasing this share by one standard deviation $(26 \%$ increase) put them at a disadvantage of $6.77 \%$. For joiners, gender has a significant impact - being a male gives an advantage of $5.59 \%$ over being a female.

\section{INSERT TABLE 2a}

Table $2 \mathrm{~b}$ presents the earnings results. Once selection has been accounted for, the earnings of the joiner is positively affected by the earnings in $\mathrm{t}-1$ of the joiner and of the founding team and being male. Earnings prior to the startup time are the most significant factors affecting the earnings of the joiners in $\mathrm{t}+1$. An increase of $10 \%$ of the joiners' prior earnings lead to an increase of $4.7 \%$ of the joiners' earnings and an increase of $10 \%$ of the founding team prior earnings lead to an increase of $1.7 \%$ of the joiners' earnings. The marginal effects may seem small but on average joiners earn less in the startup and so, these small effects are not surprising. The marginal effect of gender is more striking: a male joiner earns $23.66 \%$ more than a female joiner ${ }^{8}$.

Kappa, Lambda and sigma are the coefficients that explain the relationship between the error term in the earnings regression and the error terms in the selection rankings. Kappa is insignificant, which means that the unobserved startup characteristics do not significantly affect the error term of the earnings regression. Lambda is significant meaning that unobserved joiner characteristics affect both the joiners' selection and their earnings. Sigma square, the variance of the residuals of the error term is also significant, meaning that other factors outside the selection still affect the earnings. Overall, it means that the unobserved characteristics of the startups is a not a source of endogeneity in the earnings equation while the unobserved characteristics of the joiners are. Unobserved factors that affect selection also affect their earnings, justifying the use of our estimation approach.

\footnotetext{
${ }^{8}$ Marginal effect for dummy variables computed as follow: $100 \mathrm{x}\left(\mathrm{e}^{\gamma}-1\right)$
} 
INSERT TABLE $2 \mathrm{~b}$

\section{CONCLUSION AND DISCUSSION}

While human capital is crucial for startups' survival and growth, little is known about the acquisition of talents by startups through hiring. This study uses a two-sided matching model to identify startups' and joiners' characteristics that affect the mutual selection in the labor market. While we expected that a large number of human capital characteristics affect selection and earnings, we find that both outcomes are driven by a relatively small number of signals. Further, we found that the determination of the hiring decision is largely separate from the determination of earnings as they are driven by different human capital characteristics. Larger and college educated founding teams are more likely to attract joiners while joiners with more extensive target industry experience are preferred. We did not find evidence that any finer-grain signals of quality matter for selection. Further, we found that earnings of new hires are driven by prior earnings of the individuals and prior earnings of the founding team. Human capital characteristics that affect selection do not affect earnings after selection is controlled for. This has important implications for our understanding of the hiring in the entrepreneurial context. It appears that wage and hiring decisions are largely independent. Factors that likely play a role when deciding on compensation in an established firms such the employee's relevant experience do not seem to matter for short term entrepreneurial compensation. The reliance on signals is likely driven by high uncertainty and noisiness of the signals (Bidwell and Mollick, 2015) in an entrepreneurial setting. The separation between the drivers of earnings and selection is likely driven by the fact that a large portion of the compensation in an entrepreneurial context comes from the expectation of future growth or non-pecuniary benefits.

These results are important because, in conjunction with prior work, they provide a richer perspective on the growth of entrepreneurial startups. Startups with founders who have target 
industry experience might perform better (e.g. Delmar \& Shane, 2006) but this does not necessarily imply that the factors provide useful signals when it comes to hiring of new employees. Also, startups with prior entrepreneurial experience might be able to attract investors (e.g. Shane \& Stuart, 2002) but it may matter less when it comes to hiring. By contrast, characteristics that obvious to the potential hires such as, size and education, are the key characteristics that attract high quality joiners. On the joiners' side, as expected, joiners with target industry experience are more attractive as potential hires.

More surprisingly, being a male is the second characteristic that helps joiners being selected and gives them a consequent advantage over their female counterpart. While prior work on gender differences in entrepreneurship has focused on access to funding (Brush et al., 2014), this result sheds light on the access to entrepreneurial jobs and clearly shows that male joiners also have a consequential advantage over women. This fuels the debate on whether startups are a favorable work place for women (Khazan, 2015).

Because we found that founding teams with foreigners are less attractive, the results could also suggest that startups and joiners might be preferred because they are part of the dominating majorities, respectively, U.S. citizens and male, which relates to higher status and more connections (Lin, 2000). The founding team's U.S. citizenship decreases also the uncertainty regarding the future of the startup in comparison to founders with temporary work permits. Another interpretation that would require additional research is the existence of a bias in the startup world of technological manufacturing industries against older, foreign and female actors.

As for joiners' earnings in the startup, we find that joiners who leave an incumbent firm for entrepreneurship still expect to obtain earnings that are proportional to what they earned before. In other words, what gets joiners a job (e.g. experience) is not what affects their earnings (e.g., prior earnings). It is not surprising to see that prior earnings would be the main factor affecting earnings 
in the startup because even if there are variations between earnings in incumbent firms and in startups, the distributions may be similar. An employee who is in the top 5\% earners in an incumbent firm is likely to remain in the top 5\% in a startup, which would be consistent with the stability of ability over time. The fact that the combination of the founding teams' and joiners' experiences has no influence suggest that either the combination has not played out (yet) to be reflected in the earnings or that value created from this combination is not reflected in the joiners' short-term earnings for other reasons. In this latter case, the startups might be the ones appropriating the value. After all, in the context of technological manufacturing industries, the startups and their founding teams own most of the tangible and intangible complementary assets that affect value appropriation (Teece, 1988; Campbell et al., 2012a).

Being male positively affects the earnings as well, which shows that earnings structure and disparities based gender are also present in the context of technological startups. It is interesting to note that the male effect is significant even when controlling for prior earnings. The prior earnings control should address the alternative explanation for gender differences based on different organizational occupation (e.g. stereotype: female secretary vs. male engineer). Our other controls also challenge the explanations based on different levels of education or experience due to family leaves, for instance. When women leave the corporate world and start their own business to escape glass ceiling, self-employment or startup creation is often viewed as a solution (e.g. Boden, 1996; Kephart \& Schumacher, 2005) while the results suggest that being joiner is not.

\section{Limitations and future research}

The strength of the matching model is in presenting clear and concise results that explain hiring as a two-sided selection. In this regard, the model surpasses the use of a discrete choice model. However, two-sided matching models, like discrete choice models, rely on a few strong assumptions, especially concerning the pool of available choices the agents consider. The models do 
not take into account the stage where startups and joiners have to identify their potential counterparts. As researchers, we make the assumption that the agents know all their possible choices and consider all of them. In this context, it means that joiners know all the startups who are hiring in their market - a given state, industry and year. Similarly, the startups encounter all joiners they could potentially hire. Because this study focuses on a specific segment of the labor market of small size (i.e., on average, sixty joiners and fifteen startups per market), the assumption appears reasonable. Still, the assumption opens up opportunities for future research that could use personal networks to define the pool of potential counterparts (Granovetter, 1981). This future research would be relevant on even more specific labor markets such as the Silicon Valley.

The second assumption is that all agents have the same view of what determines the most attractive counterpart. In that sense, the preferences and underlying rankings are absolute in the sense that every agent in each side shares the same ranking. This relies on the fact that all startups and joiners want to maximize the same type of utility for which a best counterpart exists. While this assumption seems strong, it does not prevent the identification of important general characteristics such as experience, education and gender on the labor market. To study choices based on expectation to realize specific outcome, more specific characteristics might be needed as well as a model that allows flexibility in the ranking. An example could be pharmaceutical firms having different strategy to enter a new therapeutic class and therefore, looking for pairing up with partners with different resources and know-how.

The third assumption of this matching model is that there is no transfer allowed between joiners and startups to potentially work with a better counterpart than what the ranking would allow them to obtain. In other words, the assumption is that all the agents would only pair up with the best agent they could get and not with a lower ranked agent who can offer higher pay or who would accept lower pay. This offers an opportunity for future research to use matching models with 
explicit transfer estimation ${ }^{9}$ and datasets with ownership information to better capture the startup hiring process. Doing so will also help identify how much of the value is appropriated by the founding team and by the joiners.

Regarding the data, the use of U.S. Census data permits us to cover all the startups of a given industry in a given time period. This increases the generalization of the results but comes with the trade-off of missing fine-grained information. Future research can collect more information on the occupations and functional background to capture a richer phenomenon of human capital building in startups (Beckman \& Burton, 2008).

\section{Further implications}

Prior studies on pre-founding work experience show that pre-founding experience in the target industry or industry of the startup is positively associated with startup performance (Eisenhardt and Schoohoven, 1990; Agarwal et al., 2004; Delmar and Shane, 2006; Chatterii, 2009). It is unclear, however, whether startups without target industry experience could reverse the trend. This paper does not directly test if the acquisition of talent reverses the trend but shows that startups with high education and growth potential can acquire talent with target industry experience regardless of their own experience.

Prior research in entrepreneurship and strategy explained phenomena by focus on the characteristics of one of the actors. This paper contributes to the emerging research that focuses on understanding choices as mutual selection (Mindruta, 2013; Mindruta et al., 2014). The paper also expands the use of matching models to explain mutual selection and the resulting outcome (Chen, 2013; Sørensen, 2007). While, prior research studied entrepreneurs' earnings (Braguinsky et al., 2012;

\footnotetext{
${ }_{9}^{9}$ Note that two-sided matching models with Fox estimator take into consideration transfers but they cancel each other out and do not require data on these transfers and therefore, do not estimate the effect of given transfers such as stock options for instance.
} 
Campbell, 2013), little is known about the characteristics that influence earnings of workers joining startups. This paper addresses this gap while using a method that allows to explicitly separate selection and the determination of earnings. The results show that controlling for selection, prior earnings of the joiners and of the founding team, as well as gender are the main drivers of joiners' earnings in a startup. This result also connects with prior work in labor economics and sociology on the weight of prior earnings structure and disparities (Altonji \& Blank, 1999; McCall, 2001). Despite their new and more dynamic environment, startups set up remuneration system conducive to disparities.

\section{Practical implications}

This research has practical implications for startups and potential joiners as well as for policy makers. As for startups, it informs them about potential strategies in hiring talented individuals. More specifically, to appear as an attractive employer, startups have to show high education and growth potential rather than extensive experience. Similarly, for joiners, this research helps them understand what characteristics make them attractive for startups and what characteristics will affect their earnings. Joiners have to have acquired prior experience. In an ideal case, potential joiners would build their experience in incumbent firms where they do not extensively trade earnings to acquire this experience because their earnings in the startup are based on the earnings gained in the incumbent firm. This research also informs policy makers of the importance of target industry experience for the labor force to be attractive to startups. In other words, policies that facilitate access to internships in technological industries should be beneficial for startups as it would provide early industry experience that can lead to a permanent position and thus, longer experience. The second important characteristics, being a male is more problematic. Ideally, policy makers should decrease the effect of this characteristic to limit discrimination. This research also suggests that gender disparities affect the startups employees' earnings. As more and more attention is drawn to 
discrimination and disparities mainly based on gender in startups (Khazan, 2015), policy makers should foster specific studies in the context of startups and develop solutions. 


\section{REFERENCES}

Abowd, J.M., Kramarz, F., \& Margolis, D.N. 1999. High wage workers and high wage firms. Econometrica 67(2): 251-333.

Agarwal, R., Campbell, B., Franco, A., \& Ganco, M. 2016. What do I take with me? The mediating effect of spin-out team size and tenure on the founder-firm performance relationship. Academy of Management Journal 59(3): 1060-1087.

Agarwal, R., Echambadi, R., Franco, A. M., \& Sarkar, M. 2004. Knowledge transfer through inheritance: Spin-out generation, development, and survival. Academy of Management Journal, 47(4): 501-522.

Akkus, O., J.A. Cookson, A. Hortacsu. 2015. The determinants of bank mergers: A revealed preference analysis. Management Sci. Online on Nov. 24 2015.

Altonji, J. G., \& Blank, R. M. 1999. Race and gender in the labor market. Handbook of labor economics, 3: 3143-3259.

Beckman, C. M., \& Burton, M. D. 2008. Founding the future: Path dependence in the evolution of top management teams from founding to IPO. Organization Science, 19(1): 3-24.

Bidwell, M. \& Mollick, E. 2015. Shifts and ladders: Comparing the role of internal and external mobility in managerial careers. Organization Science, 26 (6): 1629-1645.

Boden, R.J. 1996. Gender and self-employment selection: An empirical assessment. The Journal of Socio-Economics, 25(6): 671-682.

Braguinsky, S., Klepper, S., \& Ohyama, A. 2012. High-tech entrepreneurship. Journal of Law and Economics, 55(4): 869-900.

Campbell, B. A., Coff R. W., \& Kryscynski D. 2012a. Rethinking Sustained Competitive Advantage from Human Capital. Academy of Management Review 37(3):376-95.

Campbell, B. A., Ganco, M., Franco, A. M., \& Agarwal, R. 2012b. Who leaves, where to, and why worry? Employee mobility, entrepreneurship and effects on source firm performance. Strategic Management Journal, 33(1): 65-87.

Campbell, B. A. 2013. Earnings effects of entrepreneurial experience: Evidence from the semiconductor industry. Management Science, 59(2), 286-304.

Cardon, M. S., \& Stevens, C. E. 2004. Managing human resources in small organizations: What do we know? Human resource management review, 14(3), 295-323.

Chatterii, A. K. 2009. Spawned with a silver spoon? Entrepreneurial performance and innovation in the medical device industry. Strategic Management Journal, 30(2): 185-206.

Chen, J. 2013. Estimation of the loan spread equation with endogenous bank-firm matching. Advances in Econometrics, 31: 251-289.

Clarysse, B., \& Moray, N. 2004. A process study of entrepreneurial team formation: The case of a research-based spinoff. Joumal of Business Venturing, 19(1): 55-79.

Coff, R. W. 1997. Human assets and management dilemmas: Coping with hazards on the road to resource-based theory. Academy of Management Review, 22(2): 374-402.

Colombo, M. G., \& Grilli, L. 2005. Founders' human capital and the growth of new technologybased firms: A competence-based view. Research policy, 34(6): 795-816.

Cooper, A. C., Gimeno-Gascon, F. J., \& Woo, C. Y. 1994. Initial human and financial capital as predictors of new venture performance. Journal of business venturing, 9(5): 371-395.

Delmar, F., \& Shane, S. 2006. Does experience matter? The effect of founding team experience on the survival and sales of newly founded ventures. Strategic Organization, 4(3): 215-247. 
Doob, J. 1949. Application of the theory of martingales. Colloquium interne du CNRS Paris, 13:2327.

Eisenhardt, K. M., \& Schoonhoven, C. B. 1990. Organizational growth: Linking founding team, strategy, environment, and growth among US semiconductor ventures, 1978-1988. Administrative Science Quarterly. 504-529.

Fleming, L., \& Sorenson, O. 2001. Technology as a complex adaptive system: Evidence from patent data. Research Policy, 30(7): 1019-1039.

Fleming, L., \& Sorenson, O. 2004. Science as a map in technological search. Strategic Management Journal, 25(8-9): 909-928.

Forbes, D. P., Borchert, P. S., Zellmer-Bruhn, M. E., \& Sapienza, H. J. 2006. Entrepreneurial team formation: An exploration of new member addition. Entrepreneurship Theory and Practice, 30(2): 225-248.

Freedman, D. 1963. On the asymptotic behavior of Bayes estimates in the discrete case I. The Annals of Mathematical Statistics, 34(4): 1386-1403.

Freedman, D. 1965. On the asymptotic behavior of Bayes estimates in the discrete case II. The Annals of Mathematical Statistics, 36(2): 454-456.

Fudge Kamal, D., Honore, F., and Nistor, C. 2016. Status Based Equity Alliances in the Thoroughbred Horse Industry: A Two-Sided Matching Approach (August 19, 2016). Available at SSRN: http://ssrn.com/abstract=2826704

Gale, D., \& Shapley, L. S. 1962. College admissions and the stability of marriage. The American Mathematical Monthly, 69(1): 9-15.

Gambardella, A., Ganco, M., \& Honoré, F. 2014. Using what you know: Patented knowledge in incumbent firms and employee entrepreneurship. Organization Science, 26(2): 456-474.

Ganco, M. 2013. Cutting the Gordian knot: The effect of knowledge complexity on employee mobility and entrepreneurship. Strategic Management Journal, 34(6): 666-686.

Gelfand, A. E., Hills, S. E., Racine-Poon, A., \& Smith, A. F. 1990. Illustration of Bayesian inference in normal data models using Gibbs sampling. Journal of the American Statistical Association, 85(412): 972-985.

Geroski, P. A., Mata, J., \& Portugal, P. 2010. Founding conditions and the survival of new firms. Strategic Management Journal, 31(5): 510-529.

Geweke, J. 1999. Using simulation methods for Bayesian econometric models: Inference, development, and communication. Econometric Reviews, 18(1): 1-73.

Granovetter, M. 1981. Toward a sociological theory of income differences. Sociological Perspectives on Labor Markets, ed. Berg, I. Academic Press New York: 11-47

Hanks, S. H., Watson, C. J., Jansen, E., \& Chandler, G. N. 1993. Tightening the life-cycle construct: A taxonomic study of growth stage configurations in high-technology organizations.

Entrepreneurship: Theory and Practice, 18(2): 5-30.

Hsu, D.H., 2007. Experienced entrepreneurial founders, organizational capital, and venture capital funding. Research Policy, 36(5): 722-741.

Jovanovic, B. 1979. Job matching and the theory of turnover. The Journal of Political Economy, 87(5): 972-990.

Katila, R., \& Ahuja, G. 2002. Something old, something new: A longitudinal study of search behavior and new product introduction. Academy of management journal, 45(6): 1183-1194.

Katz J.A. \& Welbourne T.M. 2002. Managing People in Entrepreneurial Organiztions. Advances in Entrepreneurship, Firm Emergence and Growth, Volume 5

Kephart, P. \& Schumacher L. 2005. Has the 'glass ceiling' cracked? An exploration of women 
entrepreneurship. Journal of Leadership \& Organizational Studies 12(1): 2-15.

Khazan, O. 2015. The sexism of startup land. The Atlantic, March 12th

Lin, N. 2000. Inequality in social capital. Contemporary sociology, 29(6): 785-795.

McCall, L. 2001. Sources of racial wage inequality in metropolitan labor markets: Racial, ethnic, and gender differences. American Sociological Review, 66(4): 520-541.

Mindruta, D. 2013. Value creation in university-firm research collaborations: A matching approach. Strategic Management Joumal, 34(6): 644-665.

Mindruta, D., Moeen, M., \& Agarwal, R. 2014. A two-sided matching approach for partner selection and assessing complementarities in partners' attributes in inter-firm alliances. Strategic Management Journal, 37(1) 206-231.

Pan, Y. 2015. The determinants and impact of executive-firm matches. Management Sci, online on Dec $18^{\text {th }} 2015$.

Parent, D. 2000. Industry-specific capital and the wage profile: Evidence from the national longitudinal survey of youth and the panel study of income dynamics. Journal of Labor Economics, 18(2): 306-323.

Park, M. 2013. Understanding merger incentives and outcomes in the US mutual fund industry. Journal of Banking \& Finance, 37(11): 4368-4380.

Ployhart, R. E., \& T. P. Moliterno. 2011. Emergence of the human capital resource: A multilevel model. Academy of Management Review 36.1 (2011): 127-150.

Reynolds, L.G. 1951. The structure of labor markets: Wages and labor mobility in theory and practice. Wesport, CT: Greenwood.

Roach, M., \& Sauermann, H. 2015. Founder or joiner? The role of preferences and context in shaping entrepreneurial interests. Management Science, 61(9): 2160-2184.

Roberts, G. O., \& A. F. M. Smith. 1994. Simple Conditions for the Convergence of the Gibbs Sampler and Metropolis-Hastings Algorithms, Stochastic Processes and Their Applications. 49 207-16.

Roth, A. E., \& Sotomayor, M. A. O. 1992. Two-sided matching: A study in game-theoretic modeling and analysis. Cambridge University Press.

Ruef, M., Aldrich, H. E., \& Carter, N. M. 2003. The structure of founding teams: Homophily, strong ties, and isolation among US entrepreneurs. American Sociological Review, 68(2): 195-222.

Sapienza, H. J., Parhankangas, A., \& Autio, E. 2004. Knowledge relatedness and post-spinoff growth. Journal of Business Venturing, 19(6): 809-829.

Shah, S.K. and Pahnke, E.C., 2014. Parting the ivory curtain: understanding how universities support a diverse set of startups. The Journal of Technology Transfer, 39(5): 780-792

Shane, S. 2000. Prior knowledge and the discovery of entrepreneurial opportunities. Organization science, 11(4): 448-469.

Shane, S., \& Stuart, T. 2002. Organizational endowments and the performance of university startups. Management science, 48(1): 154-170.

Shaw, J. D., Duffy, M. K., Johnson, J. L., \& Lockhart, D. E. 2005. Turnover, social capital losses, and performance. Academy of Management Joumal, 48(4): 594-606.

Sine, W. D., Mitsuhashi, H., \& Kirsch, D. A. 2006. Revisiting burns and stalker: Formal structure and new venture performance in emerging economic sectors. Academy of Management Journal, 49(1): 121-132.

Sørensen, M. 2007. How smart is smart money? A two-sided matching model of venture capital. The Journal of Finance, 62(6): 2725-2762.

Spence, M. 1973. Job market signaling. The quarterly journal of Economics, 87(3): 355.

Teece, D.J., 1988. Capturing value from technological innovation: Integration, strategic partnering, 
and licensing decisions. Interfaces, 18(3): 46-61.

Ucbasaran, D., Lockett, A., Wright, M., \& Westhead, P. 2003. Entrepreneurial founder teams:

Factors associated with member entry and exit. Entrepreneurship Theory and Practice, 28(2): 107-128.

Weiss, A. 1995. Human capital vs. signaling explanations of wages. The Joumal of Economic Perspectives, 9(4): 133-154.

Wezel, F. C., Cattani, G., \& Pennings, J. M. 2006. Competitive implications of interfirm mobility. Organization Science, 17(6): 691. 


\section{FIGURES}

Figure 1 Startup timeline

Startup timeline

( $Q=$ quarter)

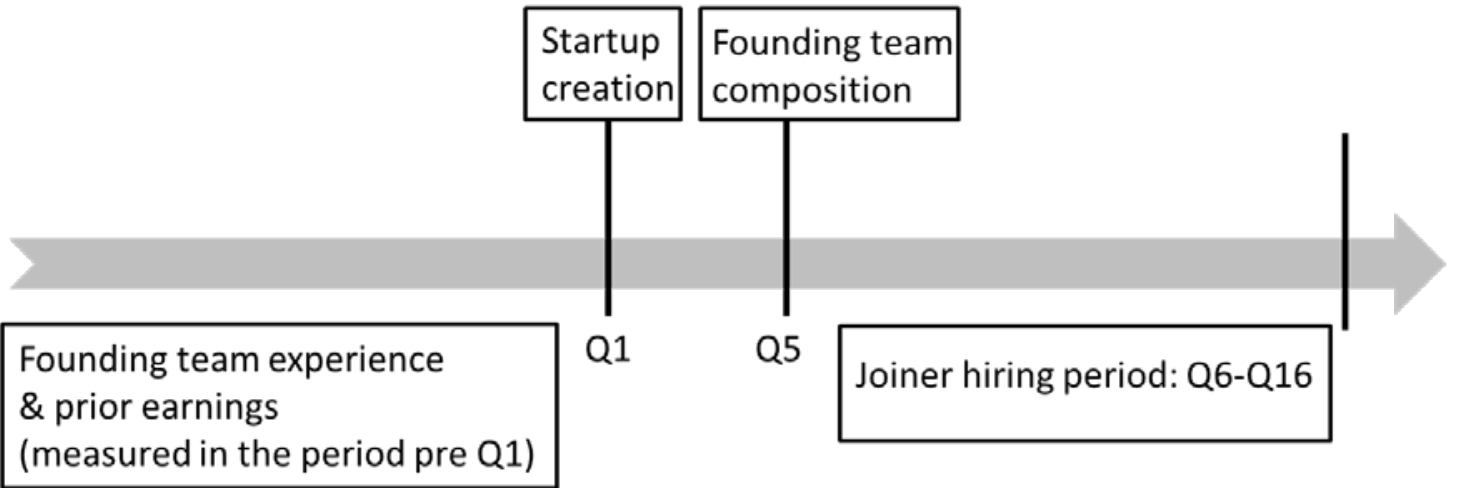

Figure 2 Joiner timeline

Joiner timeline

$(\mathrm{Q}=$ quarter, for the

corresponding startup time)

Joiner experience \& prior earnings

(measured in the period pre-year $\mathrm{t}$ )

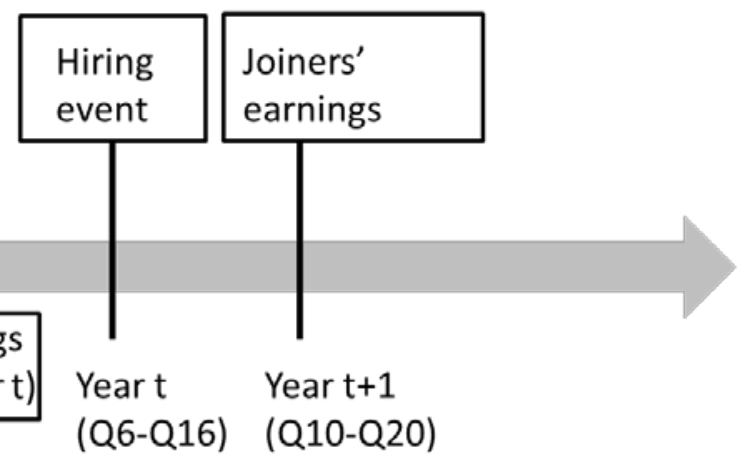


TABLES

Table 1 Descriptive statistics for the startups and joiners with t-test

\begin{tabular}{|c|c|c|c|c|c|c|c|}
\hline Start-up $(n=1000)$ & Mean & Std. dev. & Joiner $(n=4000)$ & Mean & Std. dev. & t-statistics & p-value \\
\hline Share of college-educated team members & 0.21 & 0.20 & College degree & 0.31 & 0.46 & -9.94 & $* * *$ \\
\hline Av. target ind. exp. & 1.84 & 2.27 & Target ind. exp. & 3.06 & 4.21 & -12.43 & $* * *$ \\
\hline Team average \# of entrepreneurial exp. & 0.49 & 0.55 & Average \# of entrepreneurial exp. & 0.49 & 0.90 & -0.12 & \\
\hline Team's average earnings $\mathrm{s}_{\mathrm{t}-1}(\mathrm{log})$ & 10.67 & 0.73 & Earnings $_{\mathrm{t}-1}(\log )$ & 11.42 & 0.49 & -31.58 & $* * *$ \\
\hline Team size & 7.83 & 6.51 & Joiner's earnings $\mathrm{s}_{\mathrm{t}+1}(\log )$ & 11.19 & 0.83 & NA & \\
\hline Av. age & 39.48 & 6.56 & Age & 41.60 & 9.52 & -8.33 & $* * *$ \\
\hline Share of male team member & 0.80 & 0.21 & Gender & 0.87 & 0.34 & -7.25 & $* * *$ \\
\hline Share of white & 0.66 & 0.32 & White & 0.69 & 0.46 & -2.23 & $* * *$ \\
\hline Share of foreigners & 0.20 & 0.26 & Foreigner & 0.22 & 0.41 & -1.52 & \\
\hline $\begin{array}{l}\text { Number of new establishments } \\
\text { in the startup county (log) }\end{array}$ & 8.93 & 1.83 & & & & & \\
\hline
\end{tabular}

$*, * *, * * *$ significant at $10 \%, 5 \%$ and $1 \%$ two-sided test. 
Table 2a Matching model of selection

\begin{tabular}{|c|c|c|c|c|}
\hline Variables & Mean & Std. dev. & & Probability advantage \\
\hline \multicolumn{5}{|l|}{ Start-up } \\
\hline Share of college-educated team members & 0.3262 & 0.1554 & $* *$ & 3.68 \\
\hline Av. target ind. exp. ( $>0 \&<=2$ years $)$ & 0.0433 & 0.0792 & & 2.44 \\
\hline Av. target ind. exp. ( $>2 \&<=4$ years $)$ & 0.0563 & 0.0944 & & 3.17 \\
\hline Av. target ind. exp. $(>4 \&<=6$ years $)$ & 0.1059 & 0.1120 & & 5.97 \\
\hline Av. target ind. exp. (>6 years) & 0.1601 & 0.1362 & & 9.01 \\
\hline Team average \# of entrepreneurial exp. & 0.0089 & 0.0598 & & 0.28 \\
\hline Team's average earningst $\mathrm{t}_{\mathrm{t}-1}(\mathrm{log})$ & 0.0056 & 0.0240 & & 0.23 \\
\hline Team size & 0.0078 & 0.0047 & * & 3.10 \\
\hline Av. age ( $>=30$ and $<41$ years) & -0.1017 & 0.1307 & & -5.73 \\
\hline Av. age ( $>=41$ and $<51$ years) & -0.2308 & 0.1372 & $*$ & -12.96 \\
\hline Av. age $(>=51$ years $)$ & -0.2073 & 0.1870 & & -11.66 \\
\hline Share of male team member & 0.1366 & 0.1462 & & 1.65 \\
\hline Share of white & -0.2048 & 0.1351 & & -3.73 \\
\hline Share of foreigners & -0.4555 & 0.1599 & $* * *$ & -6.77 \\
\hline \multicolumn{5}{|l|}{ Joiner } \\
\hline College degree & 0.0497 & 0.0386 & & 2.80 \\
\hline Target ind. exp. ( $>0 \&<=2$ years $)$ & -0.0024 & 0.0602 & & -0.14 \\
\hline Target ind. exp. ( $>2 \&<=4$ years) & 0.1318 & 0.0643 & ** & 7.43 \\
\hline Target ind. exp. ( $>4 \&<=6$ years) & 0.0826 & 0.0650 & & 4.66 \\
\hline Target ind. exp. ( $>6$ years $)$ & 0.1216 & 0.0491 & $* *$ & 6.85 \\
\hline Average \# of entrepreneurial exp. & 0.0030 & 0.0202 & & 0.15 \\
\hline Earnings $_{t-1}(\log )$ & -0.0090 & 0.0079 & & -0.25 \\
\hline $\operatorname{Age}(>=30$ and $<41$ years $)$ & 0.0861 & 0.0659 & & 4.85 \\
\hline $\operatorname{Age}(>=41$ and $<51$ years $)$ & 0.0400 & 0.0678 & & 2.26 \\
\hline $\operatorname{Age}(>=51$ years $)$ & 0.0569 & 0.0747 & & 3.21 \\
\hline Gender & 0.0992 & 0.0522 & * & 5.59 \\
\hline White & -0.0545 & 0.0465 & & -3.08 \\
\hline Foreigner & -0.0166 & 0.0513 & & -0.94 \\
\hline Number of observations & 110000 & & & \\
\hline
\end{tabular}

For continuous variables, the probability advantage is computed with an increase of one standard deviation.

For dummy variable, it is computed with the dummy being one and is interpreted in comparison to the omitted category. $*$, **, *** significant at $10 \%, 5 \%$ and $1 \%$ two-sided test. *, **, *** significant at $10 \%, 5 \%$ and $1 \%$ twosided test. Mean and Std. Dev. are the mean and standard deviation of the simulated posterior distributions of the parameters. They are based on 18,000 simulations; the first 2,000 being discarded for burn-in. The probability advantages were computed for the matching equation as follows: $\{2 *$ [normal cumulative distribution function $\left.\left(\mathrm{X}_{\mathrm{i}} \beta-\mathrm{X}_{\mathrm{i}} \beta\right) / 2^{\wedge} .5\right\}-1 \forall \mathrm{i} \neq \mathrm{i}$ using a one standard deviation increase from the summary statistics for continuous variables. The marginal effects for the price equation were computed with the increase of one standard deviation from the summary statistics for continuous variables and as follows: $100 \mathrm{x}\left(\mathrm{e}^{\gamma}-1\right)$ for the dummy variables. 
Table 2b Matching model of wage outcome (log earningst +1$)$

\begin{tabular}{|c|c|c|c|}
\hline Variables & Mean & Std. dev. & \\
\hline \multicolumn{4}{|l|}{ Startup } \\
\hline Constant & 3.12 & 1.17 & $* * *$ \\
\hline Share of college-educated team members & 0.19 & 0.22 & \\
\hline Av. target ind. exp. ( $>0 \&<=2$ years $)$ & 0.05 & 0.12 & \\
\hline Av. target ind. exp. ( $>2 \&<=4$ years $)$ & -0.02 & 0.14 & \\
\hline Av. target ind. exp. $(>4 \&<=6$ years $)$ & 0.00 & 0.16 & \\
\hline Av. target ind. exp. ( $>6$ years) & -0.09 & 0.20 & \\
\hline Team average \# of entrepreneurial exp. & -0.08 & 0.09 & \\
\hline Team's average earnings $\mathrm{s}_{\mathrm{t}-1}(\log )$ & 0.17 & 0.07 & $* *$ \\
\hline Team size & 0.01 & 0.01 & \\
\hline Av. age $(>=30$ and $<41$ years $)$ & 0.13 & 0.23 & \\
\hline Av. age $(>=41$ and $<51$ years $)$ & 0.10 & 0.24 & \\
\hline Av. age $(>=51$ years $)$ & 0.15 & 0.31 & \\
\hline Share of male team member & 0.04 & 0.22 & \\
\hline Share of white & 0.01 & 0.20 & \\
\hline Share of foreigners & 0.06 & 0.25 & \\
\hline \multicolumn{4}{|l|}{ Joiner } \\
\hline College degree & 0.06 & 0.09 & \\
\hline Target ind. exp. ( $>0 \&<=2$ years) & 0.10 & 0.14 & \\
\hline Target ind. exp. ( $>2 \&<=4$ years) & 0.12 & 0.15 & \\
\hline Target ind. exp. ( $>4 \&<=6$ years) & 0.12 & 0.15 & \\
\hline Target ind. exp. (>6 years) & 0.08 & 0.12 & \\
\hline Average \# of entrepreneurial exp. & 0.03 & 0.04 & \\
\hline Earnings $_{\mathrm{t}-1}(\log )$ & 0.47 & 0.09 & $* * *$ \\
\hline Age $>=30$ and $<41$ & 0.05 & 0.15 & \\
\hline Age $>=41$ and $<51$ & 0.03 & 0.15 & \\
\hline Age $>=51$ & 0.02 & 0.17 & \\
\hline Gender & 0.21 & 0.12 & $*$ \\
\hline White & 0.15 & 0.11 & \\
\hline Foreigner & 0.04 & 0.12 & \\
\hline \multicolumn{4}{|l|}{ Controls } \\
\hline \# new establishments in the startup county (log) & -0.01 & 0.03 & \\
\hline year dummies & Included & & \\
\hline region dummies & Included & & \\
\hline industry dummies & Included & & \\
\hline Kappa & -0.04 & 0.06 & \\
\hline Lambda & 0.06 & 0.04 & $\wedge$ \\
\hline Sigma square & 0.06 & 0.00 & $* * *$ \\
\hline Number of observations & 4000 & & \\
\hline
\end{tabular}

Note after Table $2 \mathrm{a} .{ }^{\wedge} 10 \%$ significant with a one-sided test for lambda, which is assumed to have a truncated distribution to identify the signs of the model. 


\section{APPENDIX}

\section{Table A.1 Industries at three-digit (bold) and four-digit levels}

Fabricated Metal Product Manufacturing

Forging and Stamping

Cutlery and Handtool Manufacturing

Architectural and Structural Metals Manufacturing

Boiler, Tank, and Shipping Container Manufacturing

Hardware Manufacturing

Spring and Wire Product Manufacturing

Machine Shops; Turned Products; and Screw, Nut, and Bolt Manufacturing

Coating, Engraving, Heat Treating, and Allied Activities

Other Fabricated Metal Product Manufacturing

\section{Machinery Manufacturing}

Agriculture, Construction, and Mining Machinery Manufacturing

Industrial Machinery Manufacturing

Commercial and Service Industry Machinery Manufacturing

Ventilation, Heating, Air-Conditioning, and Commercial Refrigeration Equipment Manufacturing

Metalworking Machinery Manufacturing

Engine, Turbine, and Power Transmission Equipment Manufacturing

Other General Purpose Machinery Manufacturing

\section{Computer and Electronic Product Manufacturing}

Computer and Peripheral Equipment Manufacturing

Communications Equipment Manufacturing

Audio and Video Equipment Manufacturing

Semiconductor and Other Electronic Component Manufacturing

Navigational, Measuring, Electromedical, and Control Instruments Manufacturing

Manufacturing and Reproducing Magnetic and Optical Media

Electrical Equipment, Appliance, and Component Manufacturing

Electric Lighting Equipment Manufacturing

Household Appliance Manufacturing

Electrical Equipment Manufacturing

Other Electrical Equipment and Component Manufacturing

\footnotetext{
Transportation Equipment Manufacturing

Motor Vehicle Manufacturing

Motor Vehicle Body and Trailer Manufacturing

Motor Vehicle Parts Manufacturing

Aerospace Product and Parts Manufacturing

Railroad Rolling Stock Manufacturing

Ship and Boat Building

Other Transportation Equipment Manufacturing
} 
Table A.2 LEHD coverage

\begin{tabular}{llll}
\hline State & Region & Starting year & Ending year \\
\hline Maryland & South & 1985 & 2008 \\
Colorado & West & 1990 & 2008 \\
Idaho & West & 1990 & 2008 \\
Illinois & Midwest & 1990 & 2008 \\
Indiana & Midwest & 1990 & 2008 \\
Louisiana & South & 1990 & 2008 \\
Washington & West & 1990 & 2008 \\
Wisconsin & Midwest & 1990 & 2008 \\
North Carolina & South & 1991 & 2008 \\
California & West & 1991 & 2008 \\
Oregon & West & 1991 & 2008 \\
Florida & South & 1992 & 2008 \\
Montana & West & 1993 & 2008 \\
Georgia & South & 1994 & 2008 \\
Hawaii & West & 1995 & 2008 \\
New Mexico & West & 1995 & 2008 \\
Rhodes Island & Northeast & 1995 & 2008 \\
Texas & South & 1995 & 2008 \\
\hline
\end{tabular}

